\title{
Piloleiomiomas multiples
}

\section{Patricia Chang'1, María Lucia Monzón Quintana², Gylari Calderón Pacheco¹}

\author{
${ }^{1}$ Department of Dermatology, Hospital General de Enfermedades IGSS and Hospital Ángeles, Guatemala, ${ }^{2}$ Hospital General \\ de Enfermedades IGSS and Hospital Ángeles, Guatemala
}

Corresponding author: Dr. Patricia Chang, E-mail: pchang2622@gmail.com

Sir

We are called to evaluate a 51-year-old patient with urticaria who is hospitalized in the Hematology ward for treatment of Non-Hodgkin lymphoma. On examination, she presents with lesions of urticaria. There is also presence of a disseminated dermatosis to the left anterior thorax (Fig. 1) and upper extremities mainly right arm. Such dermatosis is characterized by multiple brown, hard and $0.6 \mathrm{~cm}$ nodular lesions (Figs. 2 and 3). The rest of the exam shows cytostatic-use secondary alopecia, melasma, nevi, and melanonychia in hands secondary to chemotherapy.

Other than the Non-Hodgkin lymphoma for which she is being treated now she has no other relevant medical history. Her family medical history is also negative.

She first noticed these lesions 20 years ago. They began as "little balls" in the right arm. At that moment, they weren't associated with any symptom such as pain or other. With time, they began growing and appearing in other parts of her body such as her chest. Nonetheless, she had never given them attention or became concerned about them.

With this information, the diagnosis of multiple piloleiomyoma is made. A skin biopsy of one of the nodules is taken to confirm the diagnosis. Biopsy results show an ill-defined, well delimited, without a capsule neoplasm comprised of spindle cells located in the dermis. At a greater magnification, it is seen that the cells are disposed in multiple directions and originate from the arrector pili muscle (Figs. 4 and 5). At a 40x it can also been seen that the cells that comprise the lesion have an eosinophilic cytoplasm and elongated nuclei (Fig. 6).
Leiomyomas are benign smooth muscle neoplasms [1]. They can appear in different areas of the body where this type of cells can be found. Their presence hast been described in the genitourinary tract, gastrointestinal tract and skin [2]. $95 \%$ of leiomyomas are found in the uterus [3]. On the other hand, $75 \%$ of extra-uterine leiomyomas are found on the skin. Skin leiomyomas represent $3-5 \%$ of all leiomyomas [4].

According to their origin, they can be classified in one of the 3 types of cutaneous leiomyomas [5]: piloleiomyomas, angioleiomyomas, and genital or nipple leiomyomas. Piloleiomyomas arise from the arrector pili muscle. On the other hand, angioleiomyomas originate from the dermal blood vessels and genital leiomyoma from the dartos, vulvar or areola. The most common type is the piloleiomyoma followed by the angioleiomyoma [6,7]. Because of their unique site of origin, each of them has different histologic characteristics [8].

Piloleiomyomas were first described in 1854 by Rudolf Virchow [9]. They are also known by the name of pilar leiomyoma. As mentioned above, they are benign smooth muscle neoplasms that originate from the arrector pili muscle.

They can appear at any age and in both men and women. They can also be solitary or multiple lesions [4]. Multiple lesions are more common and tend to appear at a younger age. Mean age at presentation is between the second and third decade of life [5]. A family history can be identified in some of the cases since their appearance can be spontaneous or familial with an autosomal dominant mode of inheritance [6]. Clinically, they present as papules or nodules with a $1-2 \mathrm{~cm}$ diameter, violaceous or brown color, firm

\footnotetext{
How to cite this article: Chang P, Monzón Quintana ML, Pacheco GC. Piloleiomiomas multiples. 2018;9(1):86-88.

Submission: 17.02.2017; Acceptance: 29.06.2017

DOI: 10.7241/ourd.20181.26
} 


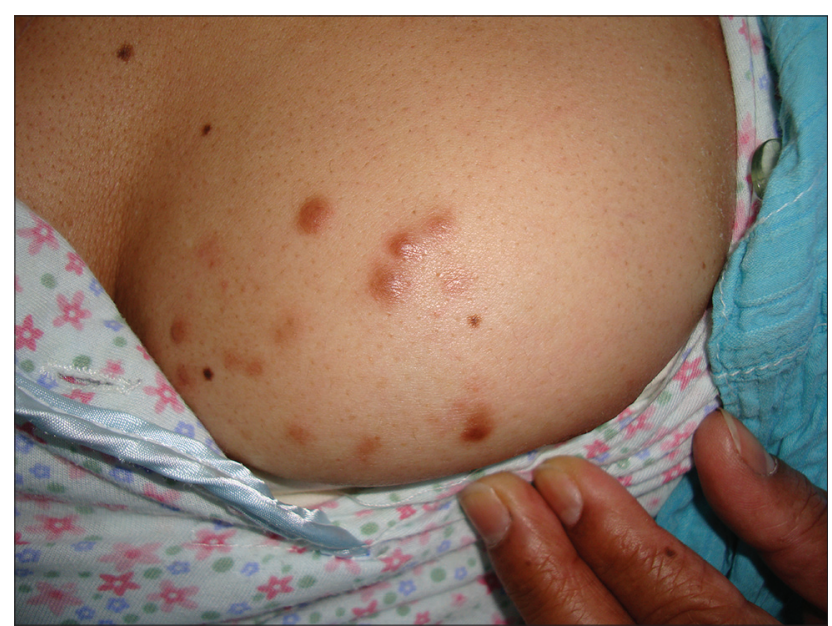

Figure 1: Nodules in left anterior thorax.

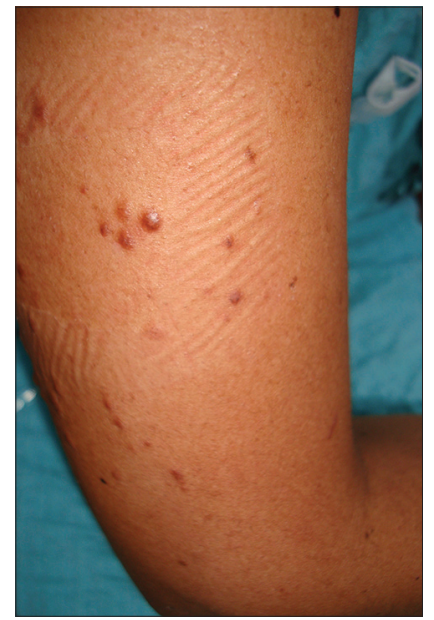

Figure 2: Multiple flesh-brown nodules in right arm.

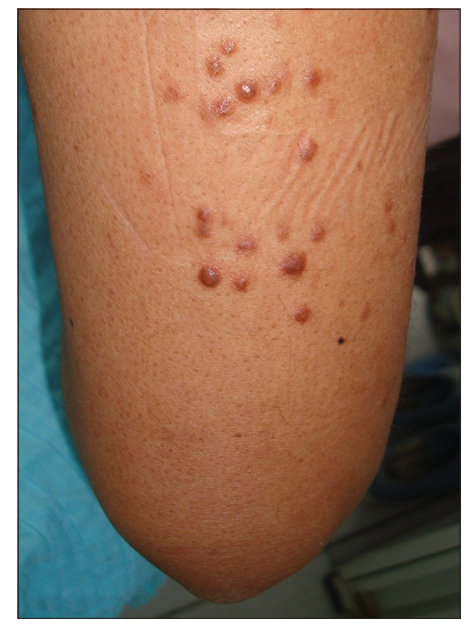

Figure 3: Multiple flesh-brown nodules in right arm.

consistency and smooth surface [7]. When there are multiple lesions they can appear following a linear or dermatomal distribution [4]. They can be found in different parts of the body [9]. The most frequently

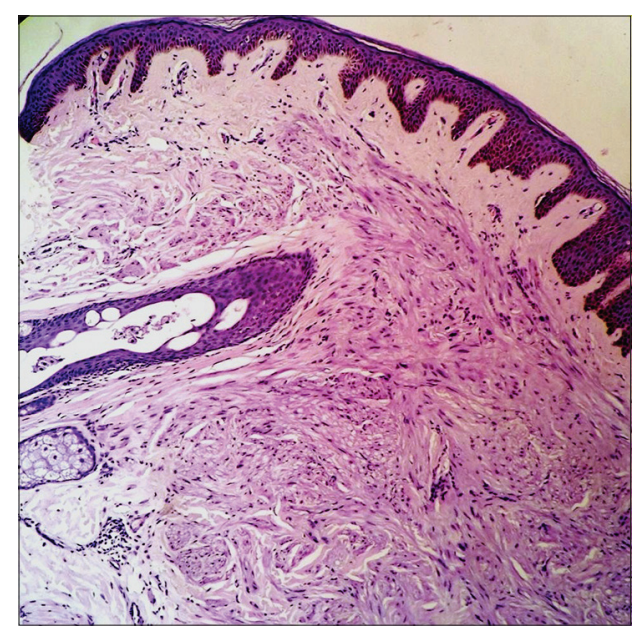

Figure 4: Well delimited, unencapsulated neoplasm in dermis comprised of bundles of spindle cells. $40 x$ magnification.

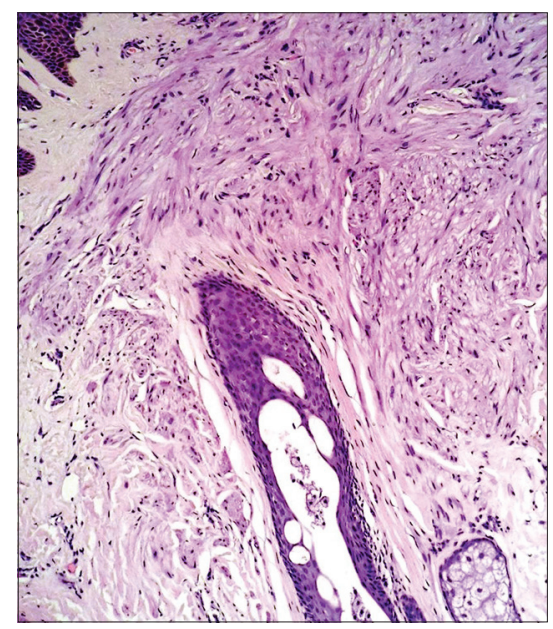

Figure 5: At a greater magnification, it can be appreciated that spindle cells are disposed in bundles following different directions and originate in the arrector pili muscle.

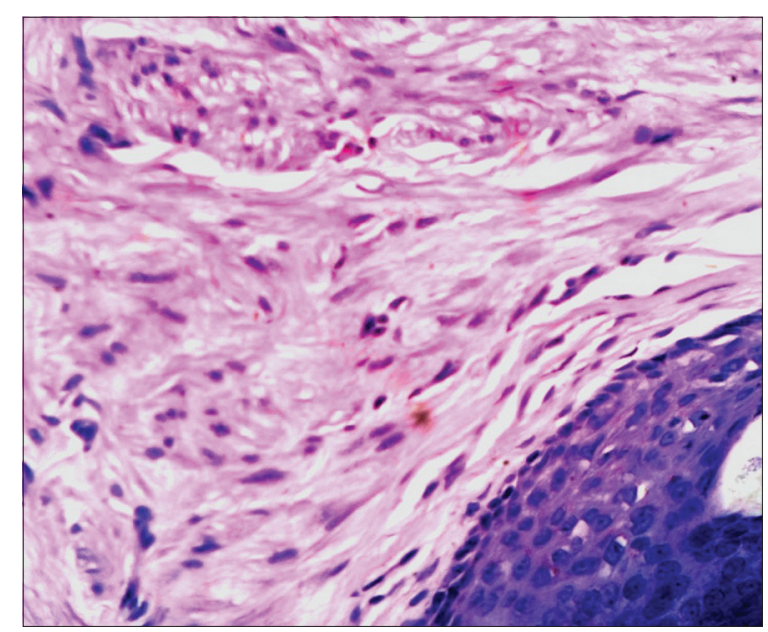

Figure 6: At a 40x magnification it can be appreciated that cells are spindleshaped, and contain an eosinophilic cytoplasm with elongated nuclei.

affected areas are extremities and trunk [5]. In the first place, they tend to appear in the extensor and proximal 
areas. Less than $1 \%$ of piloleiomyomas are found in the face or neck [4].

With time, there can appear new lesions and they also tend to grow [2]. They are painful in most cases [9]. Such sensation varies in intensity and duration. It can appear spontaneously or following trauma, pressure, cold temperatures or emotional stress $[6,10]$. The exact mechanism by which pain is caused is unknown. It has been suggested that it is the result of pressure on nerve fibers or the contraction of the muscle fibers that comprise it [2].

Differential diagnoses include: leiomyosarcoma, dermatofibroma, neurofibroma, smooth muscle hamartoma, schwannoma, angioleiomyoma, and others [6].

Definite diagnosis is made by biopsy [10]. Findings in such procedure include the presence of an ill-defined neoplasm located in the reticular dermis separated from the epidermis by an unaffected area [5]. The lesion is comprised by bundles of muscle fibers intermixed with collagen fibers [6]. The muscle fiber nuclei present important characteristics: small, central position, spindle-shaped and with blunt edges [3]. There is no presence of cellular atypia, mitosis or necrosis [10]. Smooth muscle presence can be confirmed with certain stains such as SMA, Masson trichrome and desmin.

Treatment options are variable and several aspects must be considered before deciding the best approach. Examples of such aspects include: the number and location of lesions, presence or abscence of pain or other symptoms and the patient expectations. In the case of solitary or few lesions associated with mild or no pain, chirurgic excision of the lesions is an adequate approach. Nonetheless, it is important to consider that lesions can reappear [6]. When there are multiple lesions, chirurgic excision is also an option but only for the most painful. Management of pain can include use of nitroglycerin, phenoxybenzamine and nifedipine [10]. Other treatment approaches but with limited efficaciousness include CO2 laser, cryotherapy, electrocoagulation, and others [2].

Piloleiomyomas can be associated with other medical conditions, which makes the need for a complete general evaluation important. They have been associated with uterine leiomyomas and renal cell carcinoma. When they are associated with the first, it is known as Reed syndrome [11]. The association with renal cell carcinoma is important since it tends to be aggressive in its presentation.

\section{REFERENCES}

1. Elgendy A, alshawadfy E, Ali E. Pilar leiomyoma located on the back: a case report. J Clin Exp Dermatol Resch. 2015;6:1-3.

2. Hoyt B, Tschen J, Cohen P. Solitary pilar leiomyoma of the nasal dorsum: case report and literature review. Indian J Dermatol. 2015;60:82-4.

3. Dutto S, Dupuy S, Achenbach R, Pittaro E, Jorge M, Sánchez G. Piloleiomiomas multiples. Rev Argent Dermatol. 2015;96:36-42.

4. Sousa M, Farias C, Santos I, Rocha R, Dias F, Sá H. Piloleiomyoma with segmental distribution- case report. Ann Bras Dermatol. 2015;90:170-80.

5. Young S, Park J, Gyo H, Yong C. A case of multiple piloleiomyoma on the shoulder. Arch Aesthetic Plast Surg. 2015;21:81-4.

6. Horia Morariu S, Suciu M, Alexandru Badea M. Multiple asymptomatic cutaneous pilar leiomyoma versus spontaneus eruptive keloids- a case report. Rom J Morphol Embryol. 2016;57:283-7.

7. Vaithy A, Kotasthane D. Cutaeneous leiomyoma: case study with review of literature on rare variants and clinical behavior. Int J Pharm Bio Scien. 2015;6:907-13.

8. Qadir F, Omprakash S, Dharm C, Kumari S. Cutaneous leiomyoma of scalp: a rare case report with review of literature. Int J Res Med Scienc. 2015;3:993-7.

9. Pandey I, Gupta A. Reed's syndrome: rare tumor disarray. J Post Gynecol Obstet. 2015;3:84-7.

10. Young S, Ho J, Gyo H, Yong C. A case of multiple piloleiomyoma on the shoulder which is mistaken for keloid. Arch Aesthetic Plast Surg. 2015;21:81-4.

11. Rajdeo R, Shrivastava A, Shrikhande A. Multiple cutaneous piloleiomyoma with uterine fibroids (Reed's syndrome): a rare case report. Int J Clin Bio Res. 2015;1:66-9.

Copyright by Patricia Chang, et al. This is an open-access article distributed under the terms of the Creative Commons Attribution License, which permits unrestricted use, distribution, and reproduction in any medium, provided the original author and source are credited.

Source of Support: Nil, Conflict of Interest: None declared. 